\title{
ANGELA DAVIS E A LUTA POR LIBERTAÇÃO
}

\author{
ANGELA DAVIS Y LA LUCHA POR LA LIBERACIÓN
}

\section{ANGELA DAVIS AND THE FIGHT FOR FREEDOM}

DOI: http://dx.doi.org/10.9771/gmed.v12i1.36624

Nádia Magalhães Duarte ${ }^{1}$

O livro A Liberdade é uma Luta Constante foi organizado por Frank Barat e constitui o resultado da transcrição de discursos e conferências realizadas por Angela Davis, entre os anos 2013 a 2015, a composição do livro ainda conta com material advindo de entrevistas concedidas por Angela ao próprio Frank. O resultado desse trabalho são 10 textos que nos proporciona contato com o que há de mais recente nas análises da filósofa e ativista. O lançamento ocorreu em 2016 e já em 2018 se dispunha de publicação no Brasil, a edição brasileira foi traduzida por Heci Regina Candiani. O título do livro deriva de uma canção libertária entoada constantemente por integrantes do movimento por libertação negra, no século XX, no Sul dos Estados Unidos. Davis utilizou dos versos dessa canção para iniciar um discurso, que proferiu, na Universidade de Birkbeck, em outubro de 2013.

A autora figura entre as personalidades mais influentes da atualidade por seu ativismo político e percurso acadêmico. É professora emérita do departamento de estudos feministas da Universidade da Califórnia. Angela nasceu em janeiro de 1944, na cidade de Birmingham Alabama, estado pertencente ao Sul dos Estados Unidos. Nasceu e cresceu em um estado onde vigoravam regras de segregação, da Lei Jim Crow. Sua formação acadêmica ocorreu nos Estados Unidos e Europa, tendo frequentado universidades na França e Alemanha. Participou e participa ativamente dos movimentos por libertação negra nos Estados Unidos, contribuiu com o Partido dos Panteras Negras e filiou-se ao Partido Comunista da Califórnia. Sua afiliação política foi motivo de perseguição e demissão, na primeira oportunidade do exercício da docência em 1969, o impasse com a Universidade da Califórnia foi o primeiro episódio que a lançou para projeção pública. Pouco depois foi perseguida, capturada e presa por acusações fraudulentas referentes a desdobramentos do caso Irmãos Soledad. Esse foi o fato mais emblemático na vida de Angela Davis, a motivação para tamanha atribuição reside no que foi o movimento de massas em prol de sua libertação, expresso principalmente nos Comitês Libertem Angela Davis (DAVIS, 2019). Seu percurso intelectual vai desde o estudo dos clássicos como Kant, Hegel e Marx até formulações contemporâneas como a teoria da Interseccionalidade. 
O conteúdo principal do livro provém de discursos e conferências realizadas em ocasião de alusão a datas emblemáticas da luta por libertação, bem como personalidades que se destacaram por tais lutas. De modo geral, a temática abordada é pautada pela história de luta da própria Angela Davis e outras personalidades históricas, o movimento feminista, análise crítica da movimentação por libertação negra que se formaram nos EUA, com destaque para as décadas de 60 e 70, bem como eventos políticos mais recentes da ordem das eleições de Barack Obama, movimento o Balck Lives Matter e conflitos na Palestina.

À luz das formulações da filósofa e ativista é possível tecer reflexões filosóficas, sociais e políticas acerca de nosso arranjo societário. A empreitada por estabelecer reflexões amparadas por Angela Davis deve proceder de modo que contemple o que há de mais recente em seu pensamento, expresso em A Liberdade é Uma Luta Constante, conjugado com o aparato de sua produção mais antiga.

É muito interessante o movimento que Davis realiza ao apresentar pessoas que tiveram valorosas contribuições para as lutas por transformação social, mas que foram historicamente apagadas ou apenas não lhes são atribuídos seus feitos, com o esforço de não exaltar tais indivíduos e cair no culto à personalidade. De maneira similar aborda os feitos de figuras que alcançaram reconhecimento público. Demonstra preocupação, em transmitir, como o sistema capitalista possibilita terreno fértil para exaltação de indivíduos e difusão de sentimento de individualidade. Quando questionada sobre sua prática, que exalta o coletivo, em contraditório com a lógica capitalista, que promove o individualismo, Davis argumenta que "é fundamental resistir à representação da histórica como o trabalho de indivíduos heroicos, de maneira que as pessoas reconheçam hoje sua potencial agência como parte de uma comunidade de luta sempre em expansão" (DAVIS, 2018, p.19).

A perspectiva interseccional tem recebido centralidade em suas elaborações, identifica-se, na pensadora, que a validade dessa abordagem reside principalmente na possibilidade de analisar fenômenos por meio da intersecção de múltiplas categorias. Davis centra seus esforços analíticos em torno da problemática da opressão, nesse sentido utiliza principalmente de três categorias: gênero, raça e classe. Suas análises também contemplam questões estruturais, marcos da luta por transformação social e solidariedade internacional. Acredita-se que a tradição marxista, parte importante do processo de formação formal e ativista de Angela Davis, se fez e se faz presente em suas formulações, para tanto identifica-se em sua análise no modo como opera determinados conceitos e categorias.

Davis é uma ferrenha defensora da lógica que para se envolver em uma luta contra opressões específicas não é preciso, necessariamente, ser atravessado diretamente por essas opressões. Depreende-se que essa defesa ancora-se na perspectiva de compreender que o combate às opressões é algo de interesse do gênero humano, como um todo, não apenas do grupo que se encontra subjugado pela forma de opressão específica. Ao ser questionada sobre como envolver, no enfrentamento, indivíduos que não são atingidos de forma direta por modos de opressão particular como racismo, machismo e xenofobia -, apresenta que "temos de nos livrar do pensamento 
identitário estreito se quisermos encorajar as pessoas progressistas a abraçar tais lutas como se fossem delas próprias" (DAVIS, 2018, p.40).

Em observância às ponderações estabelecidas cabe avançar e começar a discutir a ideia de feminismo que Angela prima, como de fato transformador. Na leitura de Davis o feminismo está envolto em tramas para além da igualdade de gênero. A vertente feminista à qual se associa versa de maneira consciente sobre a relação das opressões com o sistema capitalista. Compreende o feminismo como abordagem conceitual e metodológica que fornece subsídios para estratégias de transformação social e, que desse modo, possibilita estabelecer conexões entre elementos geralmente examinados separados e nem sempre aparentes. Ainda identifica no feminismo a capacidade de oportunizar desenvolvimento de estratégias epistemológicas e de organização para além das categorias mulher e gênero. Para quem se dedica à reflexão acerca do feminismo e os desafios dos movimentos sociais acredita-se que Angela Davis tem muito a contribuir, lançando luz, sobre formas de organização, atuação e potencialidades.

Nos anos 60 teve início um período emblemático de luta do povo negro com o passar do tempo surgiu disputa de como qualificar, esse período histórico, se movimento pela liberdade negra ou movimento pelos direitos civis. Davis explica que as nomenclaturas carregam importantes diferenças na leitura de mundo. O movimento pela libertação configurara algo mais amplo, carregava a perspectiva de transformação social e ruptura com o sistema imposto. Enquanto o movimento pelos direitos civis previa conquistas dentro da estrutura vigente, da ordem de adquirir direitos formais e plena participação na sociedade, não pressupunha ruptura com essa estrutura.

Sobre conquistas pontuais e individuais de membros da comunidade negra, reflete sobre a eleição de Obama que foi algo “[...] emblemático da ascensão de indivíduos negros não apenas na política, mas também nas hierarquias econômicas. $E$ isso não vai necessariamente transformar a condição da maioria das pessoas negras" (DAVIS, 2018, p.49). Estabelece limitações e potencialidades sobre o fenômeno que foi a eleição de Barack Obama, homem negro, ao cargo de presidente dos EUA.

Pondera que "não faz sentido imaginar a erradicação do racismo contra as pessoas negras sem erradicar o racismo contra as pessoas muçulmanas" (DAVIS, 2018, p.58). Corroborando desse entendimento acrescentamos a perspectiva da emancipação humana defendida na obra marxiana. Partindo dessa linha de pensamento pode-se estabelecer que seja possível auferir ganhos pontuais no que tange à liberdades limitadas para grupos particulares, que se encontram sem situação de subjugamento em função de artefato opressivo, o que se enquadra como emancipação política, a saber emancipação humana se dará no espectro de toda classe abolindo com as contradições que estruturam todos os modos opressão (MARX, 2017).

Davis desnuda a concepção de terrorismo amplamente difundida pelos meios de comunicação de ampla projeção e apresenta a tese do terrorismo como uma questão de Estado. Combate a visão propagada de que práticas terroristas são majoritariamente executadas, por determinados grupos situados na periferia do capitalista, em função de questões culturais e religiosas; 
apresenta os elementos estruturais do sistema capitalista e os interesses políticos que fomentam o terrorismo. Como o Estado e o racismo estrutural se retroalimentam, cita como mecanismos para essa retroalimentação o complexo industrial-prisional e corporações transnacionais de segurança, a exemplo a G4S.

Depreende-se que a luta deve ser antissistêmica e vislumbrar por uma organização social em que a individualidade não se expresse de maneira deteriorada por uma lógica alienada. $\mathrm{Na}$ conjuntura em que vivemos a perspectiva individualizante é exteriorizada como oportuna encontrasse disponível de modo acessível no campo da aparência. Contudo, ao cair nesse equívoco de "[...] simplesmente focar no indivíduo, como se fosse uma aberração, nós nos engajamos inadvertidamente no processo de reprodução da mesma violência que presumimos contestar" (DAVIS, 2018, p.126).

Recomenda-se a leitura atenta da obra por seu caráter didático e introdutório para reflexões sobre o combate às opressões. Identifica-se como grande potencialidade desse material a expectativa de configurar uma porta de entrada para o pensamento de Angela Davis. Compreendemos como pontos limitantes, o fato de alguns textos guardarem conexão limitada entre si e serem demasiadamente curtos o que nos deixa na expectativa do desenvolvimento mais denso de algumas afirmações e hipóteses. Os pontos limitantes apresentados podem ser facilmente identificados em obras que se propõe por realizar a reunião de discursos e textos apresentados de forma espaçada e em distintos contextos, pela proposta de formulação do livro acreditamos que é algo quase que comum em obras com proposta similar. Davis nos adverte da constância necessária na luta para alcançar liberdade, que essa deve ser uma empreitada coletiva, de modo a contemplar as singularidades e que seu caráter deve ser global e antissistêmico.

\title{
Referências
}

DAVIS, Angela. A Liberdade é uma Luta Constante. São Paulo: Boitempo, 2018.

DAVIS, Angela. Uma autobiografia. São Paulo: Boitempo, p.383, 2019.

MARX, Karl. Sobre a questão judaica. São Paulo: Boitempo, p.139, 2017.

MARX, Karl. O Capital: crítica da economia política. São Paulo: Boitempo, p.893, 2013.

\begin{abstract}
Notas
1 Graduada em Gestão de Serviços de Saúde pela Escola de Enfermagem da Universidade Federal de Minas Gerais (UFMG). Pesquisadora voluntária nos grupos Trabalho e Marxismo (TRAMA), da Universidade Federal de Juiz de Fora e Economia Política do Poder em Estudos Organizacionais (EPPEO), da Universidade Federal do Paraná, ambos com vínculo no CNPQ. CV: http://lattes.cnpq.br/8018817127630202 Contato: nadia.mduarte@hotmail.com
\end{abstract}

Recebido em: 29.04.2020

Aprovado em: 23.05.2020 